\title{
La industria automotriz de México: las expectativas de competitividad del sector de autopartes
}

Introducción

$\mathrm{M}$ éxico tiene una situación privilegiada por su mano de obra calificada y altos estándares de calidad, lo que lo convierte en una plataforma de producción y comercialización ideal para cualquier empresa en el mercado de libre comercio con Norteamérica (Tamariz, 1999).

El sector de autopartes de la industria automotriz, la segunda exportadora más importante de la economía, representa un papel fundamental. El objetivo de este artículo es diagnosticar al sector de autopartes y las expectativas de su competitividad con base en sus ventajas competitivas, según la teoría de la ventaja competitiva de Michael Porter.

La industria automotriz mexicana está formada por los sectores terminales de producción de vehículos y de autopartes. De acuerdo con datos del Instituto Nacional de Estadística, Geografía e Informática, el sector terminal representa 57\% del PIB de esta rama y el de autopartes $43 \%$; además, cuenta con más de mil fabricantes de autopartes de los cuales cerca de 70\% está conformado por empresas extranjeras y el resto por

* Egresada de la Licenciatura en Estudios Internacionales de la Universidad de Guadalajara.

Agradezco los comentarios y sugerencias de Rosario Cota Yánez. Los errores y omisiones son responsabilidad mía. empresas nacionales. Las actividades del sector terminal se enfocan principalmente al ensamble de vehículos y el sector de autopartes se encarga de la fabricación de partes y componentes automotrices. La industria automotriz es un elemento clave de la estrategia de modernización e integración de México en la economía mundial; además del dinamismo comercial que produce y de ser el sector económico que presenta el mayor superávit, ${ }^{1}$ tiene una estrecha relación con otras ramas productivas que la proveen de insumos. Los cambios en la industria automotriz mundial y el papel que ha desempeñado el gobierno mexicano desde el nacimiento de la industria automotriz en México han sido fundamentales para el desarrollo de la misma, y ayudan a entender el rápido crecimiento e internacionalización de su producción en este país.

La evolución de la industria automotriz mexicana comprende tres fases distintas (Moreno, 1995; véanse también Arteaga y Gutiérrez, 1996; Micheli, 1994; Arteaga y Micheli, 1993): a) la creación de la primera planta de montaje, b) la producción de vehículos de motor como actividad industrial y c) la búsqueda de la expansión de la industria por medio de las exportaciones. ${ }^{2}$

\section{a) El establecimiento de una industria de montaje (1925-1962)}

En 1925 la compañía Ford Motor estableció su primera planta de montaje en México;

MÉXICO YLACUENCADEL PACÍFICO

vol. 8, núm. 26 / septiembre - diciembre de 2005

33 
posteriormente, otras empresas extranjeras o de extranjeros asociados con mexicanos construyeron plantas de montaje ubicadas principalmente en la Ciudad de México. Durante este periodo la producción era intensiva en el uso de mano de obra y existía muy poca relación con otras ramas productivas de la industria nacional. La mayor parte del mercado nacional era abastecido por aproximadamente una docena de empresas de montaje que existían en el país y las principales pertenecían a Ford, General Motors (GM) y Fábricas Automex. Las compañías Ford y GM eran filiales con capital totalmente de empresas estadounidenses, en cambio Automex tenía $60 \%$ de capital mexicano en asociación con Chrysler. Era necesario alcanzar un mayor nivel de eficiencia en la industria automotriz, es decir, una disminución del número de fabricantes.

\section{b) La producción de vehículos de motor (1962-1977)}

En 1962 el gobierno mexicano promulgó un decreto que pretendía fomentar la fabricación de los vehículos y no sólo el montaje de las empresas automotrices del país. Buscaba, además, proteger la participación de las empresas mexicanas en el mercado interno mediante límites al número máximo de autos (modelos y marcas) que cada empresa producía. El decreto pretendía también incentivar la producción de piezas de automóviles de las empresas nacionales, y, como parte de esta medida, estableció que todas las empresas fabricantes de autopartes debían tener al menos $60 \%$ de capital mexicano. Con esta estrategia el gobierno trataba de proteger al capital nacional en la producción de automóviles y autopartes.

Las empresas establecieron plantas para la producción y el montaje de moto- res, ${ }^{3}$ y utilizaban un número importante de piezas y componentes de fabricación nacional. Otra característica importante de esta etapa es que las plantas estaban ubicadas alrededor de la Ciudad de México. Para 1971 sólo dos de las empresas fabricantes de automóviles contaban con capital principalmente mexicano y ambas eran de propiedad estatal: Vehículos Automotores Mexicanos (VAM) y DINA-Renault. Con esto quedaba asentado el fracaso del decreto de 1962: con excepción de las empresas que tenían participación estatal, el capital mexicano abandonó la industria automotriz y dejó el mercado en manos de las empresas multinacionales que tenían recursos tecnológicos, financieros y comerciales superiores.

En 1969 el gobierno mexicano decidió que cuando menos $50 \%$ de los costos de las importaciones de cada empresa debía ser compensado con exportaciones. El éxito de esta medida fue parcial: las exportaciones aumentaron pero las empresas no realizaron ninguna inversión nueva que pudiera ayudarles a aumentar su capacidad exportadora o mejorar su competitividad internacional. La maquinaria que existió en el país durante este periodo era tecnológicamente obsoleta. Como los fabricantes se dedicaban a abastecer exclusivamente al mercado interno, las exportaciones de la industria automotriz eran mínimas. En 1975 las exportaciones sólo cubrían 16\% de los costos totales de sus importaciones, cifra inferior al objetivo que estableció el gobierno en $1969 .{ }^{4}$

\section{c) La búsqueda de la expansión de la industria por medio de las exportaciones (1978-1989)}

En 1977 la promoción de las exportaciones se convirtió en el objetivo principal después 
de la modificación de los objetivos políticos. En ese año un decreto gubernamental presentó un presupuesto cuyo objetivo era el equilibrio de la balanza comercial respecto a cada empresa de vehículos de motor. Se incluían no sólo las importaciones directas hechas por la empresa sino también todas las importaciones representadas por piezas y componentes comprados a los abastecedores nacionales, así como otros pagos en divisas (regalías, asistencia técnica, etc.). Con esto el gobierno mexicano responsabilizaba a las empresas automotrices de reducir el déficit comercial global de la industria y condicionaba, además, la presencia de las empresas fabricantes de automóviles en el mercado nacional a su contribución en el mejoramiento de la balanza comercial de la industria automotriz. El gobierno trató de obligar a las empresas automotrices a reestructurar su producción para promover las exportaciones como fuente de expansión de la industria automotriz e implementó otras medidas para impulsar el desarrollo del sector de autopartes nacional. El decreto prescribía que al menos 50\% del monto total de las necesidades de divisas de las empresas automotrices debía proceder de exportaciones de piezas y componentes producidos por fabricantes de repuestos de automóviles (Moreno, 1995).

En consecuencia, las empresas de montaje se sentirían obligadas a impulsar las exportaciones de las autopartes producidas por empresas nacionales, ya que si no cumplían con los objetivos del decreto serían sancionadas con multas o reducciones de las subvenciones, desgravaciones y otros estímulos fiscales de los que gozaban. La respuesta de las empresas automotrices en México ante las condiciones que enfrentaban, tanto en el ámbito interno como el externo, fue el establecimiento de un nuevo conjunto de fábricas para volverse competitivas internacionalmente. La prioridad que el gobierno mexicano otorgó a la promoción de las exportaciones fue mayor que el interés por la promoción del capital nacional en la industria automotriz, pues las empresas automotrices de propiedad extranjera exportaban más que las mexicanas.

En 1983 el Estado vendió vam y 60\% de Rimex (Renault Industrias Mexicanas) a Renault-Francia con lo que el capital mexicano, después de aproximadamente 25 años, quedó excluido de la industria automotriz. Las nuevas fábricas eran muy diferentes a las que existían, se dedicaban a abastecer al mercado de Estados Unidos, las nuevas instalaciones incorporaban tecnología muy moderna, estaban altamente automatizadas y algunas disponían de robots, prensas automáticas y máquinas de control numérico, aunque seguía existiendo una estrecha relación con los procesos intensivos en mano de obra. También, la concepción de las relaciones entre la empresa y los trabajadores y sus sindicatos se había modificado; aunque nunca existió un sindicato para los obreros de toda la industria automotriz en el país, la dispersión sindical se acentúo más en este periodo. Cada planta exportadora contaba con su sindicato que era independiente de los que existían en las fábricas establecidas.

Las nuevas fábricas estaban ubicadas a menor distancia de la frontera con Estados Unidos, con excepción de Volkswagen (vw), que incorporó la expansión de su capacidad para exportar como una nueva sección de su complejo industrial, y de Chrysler, que adaptó su fábrica de Toluca para su programa de exportaciones (Moreno, 1995). A partir de 1981 se incorporan los procesos de estampado de la carrocería y con las inversiones realizadas en las nuevas plantas 
para la exportación, el adelanto tecnológico y organizacional que sufrió la industria automotriz mexicana fue significativo.

En 1988 la industria automotriz produjo 350,000 unidades y en ese mismo año la producción de vehículos (automóviles y camiones) de México representó $0.8 \%$ de la producción mundial. Esto refleja que la industria automotriz mexicana empezó a tener un desempeño exportador relevante, lo que se muestra favorablemente en la recuperación de los índices del sector externo mexicano. En diciembre de 1989 el presidente Salinas de Gortari promulgó un decreto para la modernización de la industria automotriz que modificó radicalmente las condiciones de producción y la demanda de la industria, ya que permitía una apertura gradual del mercado interno y cambiaba las reglas sobre el valor agregado mínimo que debían tener los vehículos.

En 1995 las ventas se desplomaron 66\% con respecto al año anterior y se vendieron 230,000 automóviles, el nivel más bajo en mucho tiempo, debido a la devaluación y fuga de capitales de diciembre de 1994. Sin embargo, con la entrada en vigor del Tratado de Libre Comercio de América del Norte (TLCAN) el 1 de enero de 1994, inició una nueva etapa en la industria automotriz mexicana. La ventaja que ofreció el TLCAN, al prometer la liberación de la industria automotriz en 2004 y la búsqueda de consolidación de sus operaciones en el país, provocó que las empresas automotrices establecidas en México realizaran diversos proyectos de inversión (Carrillo y Ramírez, 1997): tan sólo las inversiones de Chrysler, GM y Ford representaron cerca de 1,000 millones de dólares (MDD) en 1994.

A su vez, nuevas firmas como Honda deciden establecerse en el país, quien en 1995 inicia la producción piloto de automóviles en el Salto, Jalisco con una inversión de 50 MDD y una capacidad instalada de 15,000 vehículos al año. En 1995 la GM realizó una inversión de 400 MDD en una planta ensambladora de camiones que inició operaciones en Silao en ese año; asimismo, esta empresa invirtió $150 \mathrm{MDD}$ en un centro técnico localizado en Ciudad Juárez (Carrillo y Ramírez, 1997). La estrategia de GM no estuvo encaminada a modernizar las plantas antiguas, sino a establecer nuevas plantas para la producción de motores y el ensamble de vehículos. La firma Mercedes-Benz trajo también varios modelos, algunos con precios superiores a los 350,000 pesos e incluso versiones blindadas cuyo costo se acercaba al millón de pesos. Los vehículos de la clase $\mathrm{C}$ serían ensamblados en la planta de camiones de Mercedes-Benz ubicada en Santiago Tianguistenco, Estado de México. La empresa BMw también aprovechó el periodo de crisis para intensificar la producción de vehículos en la planta de Lerma en el Estado de México que operaba desde 1994. Esta empresa ensamblaba sus vehículos de la serie 5 y en 1995 acordó con Porsche armar hasta 30 unidades —como mínimo- de estos vehículos deportivos en la planta de BMw en México. La empresa Lamborghini inició un programa piloto para armar su modelo Countach en un laboratorio de pruebas en Atizapán, Estado de México. Este proyecto fracasó debido a los problemas fiscales entre la empresa y la Secretaría de Hacienda. En 1996 la marca Land Rover anunció que invertiría 170 MDD para ensamblar y vender sus vehículos a través de la BMw en un plazo de 10 años —en ese momento Land Rover era propiedad de la BMw y actualmente pertenece a Ford.

En 1997 llegan al mercado mexicano los vehículos de Peugeot fabricados en Chile $^{5}$ — para esta empresa era más conveniente importar los vehículos que instalar 
una fábrica en México-. Por otro lado, debido a que Jaguar es parte del consorcio Ford, esta empresa tiene una filial en México que presenta un importante superávit en la balanza comercial, desde 1997 se le permite a Ford importar vehículos de esta marca. Antes de 1995 al menos 80\% de los vehículos vendidos en México era producto nacional en tanto que al cierre de 1998 el porcentaje disminuyó a 65\% (Campos, 2003).

En 1999 la fusión entre la firma francesa Renault y la japonesa Nissan trajo como consecuencia la producción de automóviles franceses en las plantas de Cuernavaca y Aguascalientes. Para el mercado mexicano este tipo de fusiones y alianzas ha significado una gran diversificación de automóviles y, por lo tanto, que se importen más vehículos extranjeros o que se fabriquen otras marcas de vehículos en las plantas ya establecidas. Actualmente, la industria automotriz representa un elemento clave en las estrategias de modernización y globalización del país, al ser una de las industrias más ligadas a las transformaciones mundiales. En el ámbito interno la industria automotriz no sólo ha mantenido el segundo lugar en exportaciones, sino que en 2003 generó más de 31,000 MDD, y es el sector que presenta el mayor superávit, ${ }^{6}$ lo que ha impactado positivamente a la balanza comercial. Además, es de gran importancia para la economía nacional por su estrecha relación con otras ramas productivas que la proveen de insumos; entre éstas destacan la industria hulera, química, siderúrgica, del cobre, del aluminio y textil.

México también es conocido como un gran productor de camiones: según cifras de INEGI, las exportaciones de este rubro crecieron más de $30 \%$ durante el periodo 1998- 2004. En el mercado mexicano se pueden encontrar más de 33 marcas internacionales de automóviles, camiones y tracto-camiones; $55 \%$ de los vehículos que se venden son importados y el resto es producido en el país (Hernández, 2003). Esto demuestra que existe una demanda interna diferenciada. Asimismo, la industria automotriz mexicana ofrece precios competitivos, calidad en el servicio, garantía y facilidad para la adquisición de componentes con el fin de satisfacer las exigencias de los consumidores.

El mapa 1 muestra la ubicación actual de las firmas multinacionales establecidas en México. Actualmente, existen en México ocho fabricantes de vehículos con cerca de 20 plantas y más de 600 proveedores directos. Las plantas que se encuentran en los estados de Baja California, Chihuahua, Coahuila, Hidalgo, México, Guanajuato, Jalisco, Morelos, Nuevo León, Puebla, San Luis Potosí y Sonora se encargan del ensamble de los automóviles. Utilizan un alto grado de tecnología y tienen una fuerte relación con la matriz, lo que lleva a suponer que las decisiones en cuanto a inversión en innovación y desarrollo se toman fuera del país. Asimismo, se observa que las empresas ensambladoras presentan una distribución casi homogénea, resultado de las distintas fases de la evolución de la industria automotriz en México. Las primeras plantas estaban ubicadas en el centro del país debido a que esta región contaba con la infraestructura necesaria y mano de obra calificada. Con el auge exportador y la necesidad de estar más cerca del mercado de Estados Unidos se establecieron nuevas plantas en el norte del país. El establecimiento de nuevas plantas automotrices en la región centro-occidente del país se debe a la saturación de la región del centro y norte de México, así como a la creación de nuevos espacios industriales 
en ciudades que iniciaban su desarrollo económico (Rodríguez y Cota, 1999).

\section{La ventaja competitiva de Porter en el sector de autopartes mexicano}

En este apartado se presenta la estructura del sector de autopartes mexicano. $\mathrm{Su}$ objetivo es identificar el estado de los determinantes de la ventaja competitiva desde la perspectiva de Michael Porter (Porter, 1991). Esta teoría permite analizar el estado de las empresas fabricantes de autopartes en México, así como conocer si tienen los elementos que les permitan competir exitosamente tanto en el mercado interno como en el externo. De acuerdo con la teoría de la ventaja competitiva, existen cuatro elementos conocidos como el diamante de la competitividad que conforman el clima nacional en el que compiten las empresas del sector y que contribuyen a crear o entorpecer la ventaja competitiva (esquema 1): a) condiciones de los factores, b) condiciones de la demanda, c) sectores conexos y auxiliares y d) estrategia, estructura y rivalidad de la empresa. El autor presenta, además, dos factores adicionales que complementan el diamante: la casualidad y el Estado.

El sector de autopartes es un componente esencial de la industria manufacturera mexicana, porque en los últimos años se ha convertido en uno de los sectores manufactureros más dinámicos y participa con una proporción importante de las

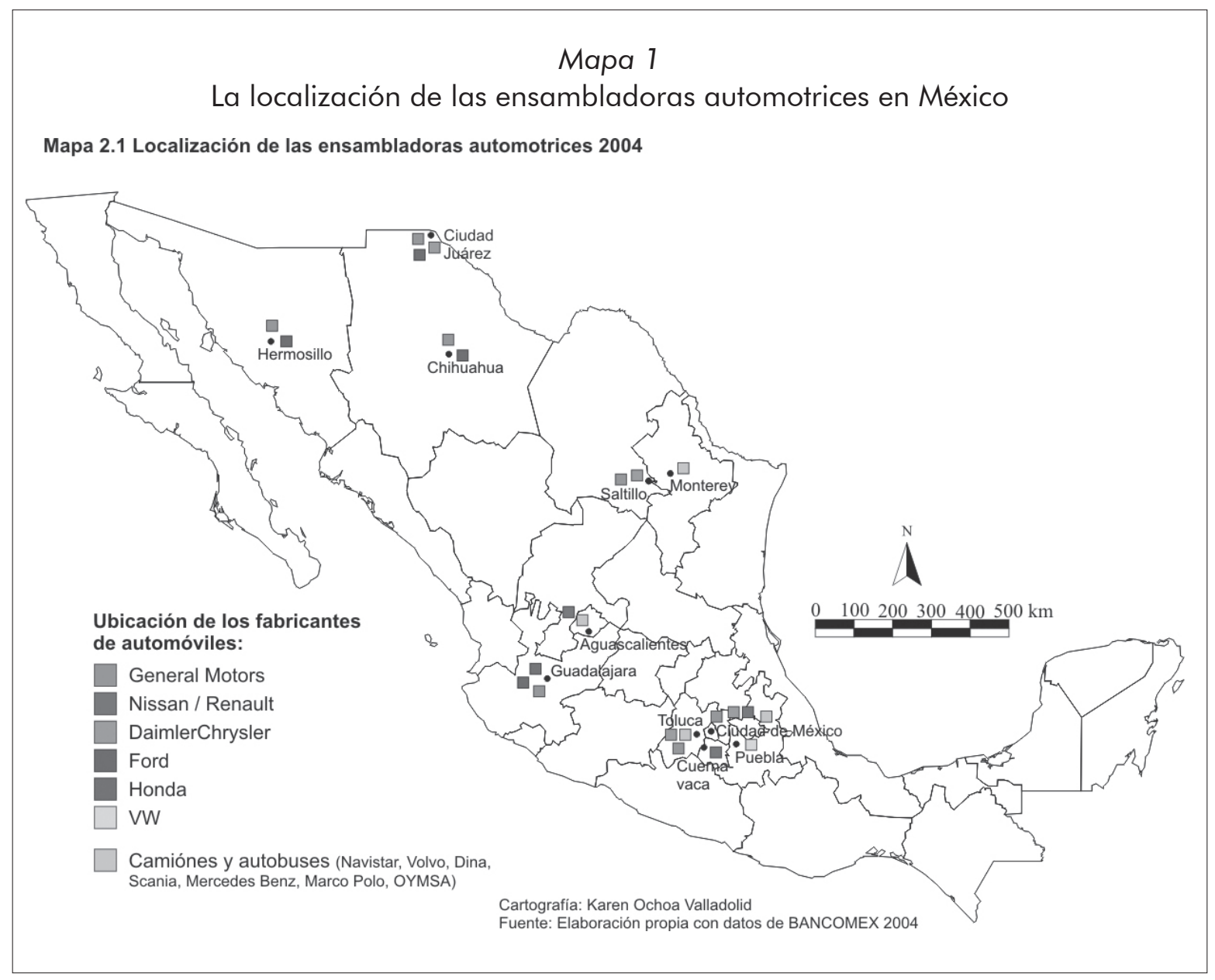

38 MÉXICO YLACUENCADEL PACÍFICO

38 vol. 8, núm. 26 / septiembre - diciembre de 2005 


\section{Esquema 1}

El diamante de la competitividad

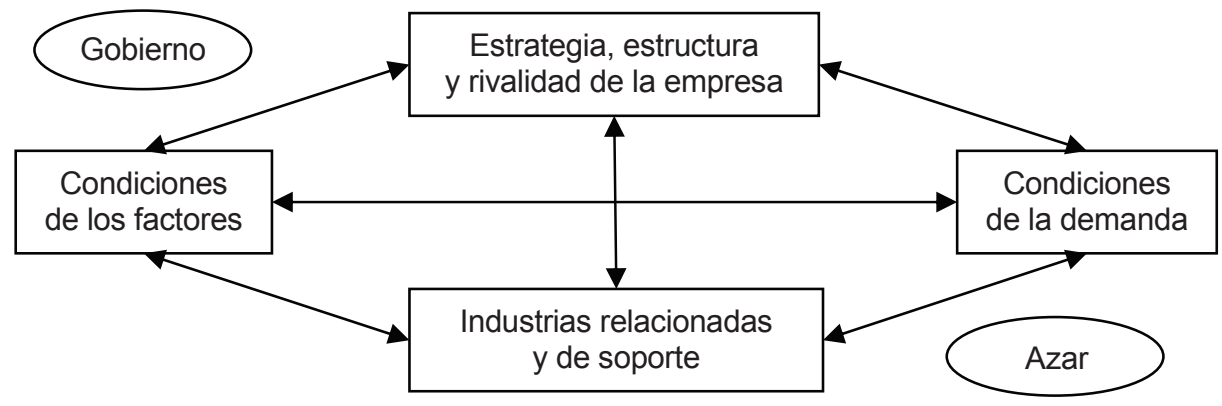

Fuente: Porter (1991: 238).

exportaciones no petroleras. La Industria Nacional de Autopartes (INA) argumenta que este sector constituye, después de la industria terminal, el segundo sector exportador más importante de la industria manufacturera mexicana. El sector de autopartes atiende a diferentes mercados como los de exportación, equipo original, refacciones y partes para motores. El mercado de equipo original provee a las armadoras de las partes de los vehículos. El mercado de exportación se divide en venta directa al extranjero y venta indirecta; ésta consiste en el envío de autos a otros países con componentes mexicanos que hacen las armadoras. En 1999 las 600 empresas fabricantes de autopartes que existían estaban registradas ante la Secretaría de Comercio y Fomento Industrial (Secofi), lo cual les permitía ser proveedores de equipo original para la industria terminal: 220 exportaban de manera directa y 47 estaban clasificadas como Altamente Exportadoras (Altex) (Morales, 2000). Actualmente, de acuerdo con cifras de la INA, el sector de autopartes está conformado por más de mil fabricantes de piezas para automóviles que dan empleo a más de 415 mil personas. Los distintos productos que estas empresas producen se destinan a la fabricación de automóviles, camiones ligeros y camiones pesados, incluyendo vehículos de autotransporte de carga y pasajeros.

\section{a) Las condiciones de los factores}

México cuenta con una gran disponibilidad de recursos naturales que le permiten dotar de insumos a otros sectores de la economía. Posee una extensión territorial de 1'964,375 km², redes de transporte desarrolladas y una infraestructura bien desarrollada. ${ }^{7}$ Los costos de propiedades y construcción son generalmente bajos en comparación con otras naciones y, por lo tanto, muy competitivos (Charles River Associates, 2003). México tiene una población de 97'483,412 habitantes ${ }^{8}$ y una fuerza de trabajo de 23'197,214 personas. Las industrias manufactureras y el comercio concentran un gran porcentaje de los trabajadores, cerca de $26 \%$ y $31 \%$, respectivamente. ${ }^{9}$ En 2000 tan sólo $12 \%$ de la población de 24 años y más contaba con algún grado de estudios superiores. ${ }^{10}$ El gasto en educación como porcentaje del PIB fue de 5.9\% en 2003, cifra importante si se compara con $2 \%$ gastado en 1997 (ocDE, 
2006); este incremento muestra el interés del gobierno mexicano por estimular la educación en el país. Sin embargo, la OCDE argumenta que los logros educativos a nivel universitario en México son aún muy bajos, en tanto sólo un pequeño porcentaje de la población cuenta con un grado universitario. En 2003 había 464,700 personas que laboraban en la industria automotriz, en el sector de autopartes había 408,500 trabajadores y en la industria terminal había 52200 trabajadores (gráfica 1).

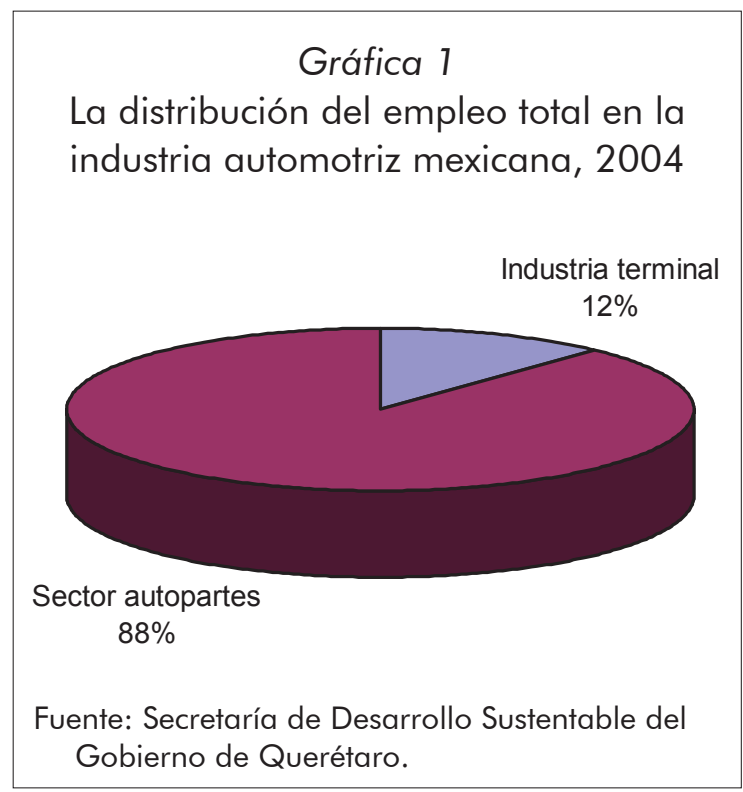

La industria automotriz - tanto en el sector terminal como el de autopartes-demanda una gran cantidad de personal altamente calificado, especialmente ingenieros y técnicos, y los jóvenes mexicanos encuentran en esta industria la oportunidad de acumular conocimientos y realizar una carrera profesional. Los bajos costos de mano de obra no calificada, semi-calificada y calificada en México, en comparación con los costos en Estados Unidos, son un factor de competitividad para la industria automotriz (Carrillo y Ramírez, 1997). Al respecto, Félix Núñez (Eggers y Arellano,
2000), director de operaciones de Ford México, afirma que los obreros mexicanos están entre los mejores del mundo, ya que sus habilidades y desempeñó se reflejan en la reducción de costos de operación y pérdida de tiempo por fallas y desajustes, por lo que, aun cuando los salarios de los obreros de Ford estén entre los más altos en el país, su impacto en los costos totales es inferior al costo de utilizar robots en todas las actividades. Es bien sabido que el actual régimen económico internacional demanda mayores niveles de educación como base de la formación de capital humano, y por esto el sistema de educación y los sistemas de formación profesional de un país, los apoyos a la investigación, así como las tradiciones que puedan contribuir con una mejora de la productividad laboral se definen, de acuerdo con la teoría de Porter, como mecanismos de creación de factores, y son muy importantes para mejorar la competitividad de una empresa o sector.

En México el Estado todavía es la institución responsable del proceso de formación de capital humano. A pesar de que está institución ha manifestado su preocupación por mejorar el sistema educativo en México, ${ }^{11}$ eliminar el rezago educativo existente y responder a la demanda de personal altamente calificado, sus esfuerzos realizados en el área educativa no han sido suficientes en comparación con los de los países desarrollados. A su vez, existe una débil vinculación entre las universidades y el sector productivo, y aún cuando las empresas reconocen la importancia de la universidad en la generación de conocimientos útiles, generalmente dan más importancia a los conocimientos que provienen del exterior que a los de las universidades del país. ${ }^{12}$ La investigación que se realiza en las universidades es generalmente de naturaleza básica y aplicada, y se realiza 
muy poca investigación experimental de actividades ligadas a nuevos productos (Correa, 2001).

En cuanto al sector de autopartes mexicano, se sabe que tiene una importante demanda de personal calificado y semi-calificado, y que los bajos costos de los salarios, como se mencionó anteriormente, son un factor de competitividad para las empresas que conforman la industria automotriz. La capacidad del Estado en la formación de recursos humanos es aún limitada y no se tienen indicios de una fuerte cooperación para investigación y desarrollo entre las universidades del país y el sector de autopartes.

Respecto a las tradiciones y aspectos culturales de los trabajadores mexicanos en el sector de autopartes, es bien conocido el "ingenio" del mexicano en la solución de problemas de corto plazo ${ }^{13}$ y esta cualidad es muy apreciada por las empresas de la industria. Por otro lado, la falta de formalidad e impuntualidad de algunas empresas mexicanas que proveen de insumos o material de embalaje al sector de autopartes mexicano y que puede llegar a afectar la productividad de éste, es tomada como un factor que resta competitividad a este sector.

\section{b) Las condiciones de la demanda}

En términos de su contribución al PIB manufacturero, el sector de autopartes ha mantenido una participación relevante a pesar de los tropiezos de la economía mexicana. En lo que respecta al valor de la producción total de autopartes en el país, el sector ha mostrado un crecimiento de 13,893 a 22,419 mDD de 1994 a 2004 , lo que representa un crecimiento de un $60 \%$ el cual se ve reflejado en la participación del sector de autopartes en valor del PIB de la industria automotriz, de acuerdo con información de la INA. El INEGI reporta que el sector de autopartes contribuye con $6.3 \%$ del PIB manufacturero, $10.2 \%$ de las exportaciones y $17.4 \%$ del personal ocupado en el sector manufacturero. El sector de autopartes provee a dos mercados: el de equipo original que se usa directamente en la fabricación de los autos nuevos, cuyos clientes son las armadoras establecidas en el país así como armadoras en el extranjero; y el de repuestos, que son las partes de refacciones que se utilizan en los talleres de reparación de vehículos.

La gráfica 2 muestra la distribución del PIB de la industria nacional de autopartes. En ella se observa que el mayor dinamismo en este sector lo presentan los motores y sus partes con $22 \%$ de participación del PIB. Las partes del sistema eléctrico se han vuelto muy importantes porque un automóvil requiere crecientemente de componentes electrónicos, que lo hacen más atractivo.

El INEGI estima que el valor total del mercado en el país, incluyendo las exportaciones e importaciones, es de aproximadamente 30,000 MDD al año. Los principales componentes requeridos por las ensambladoras automotrices son: sistemas para $\mathrm{A} / \mathrm{C},{ }^{14}$ partes de motor, sistemas de dirección, sistemas de logística, moldes y datos, y partes electrónicas. Estos componentes son fabricados en su mayoría por los proveedores de primer nivel, que a su vez encuentran en los proveedores de segundo y tercer nivel sus fuentes de insumo. Los componentes requeridos por los proveedores de primer nivel son generalmente: forjas, estampados, plásticos, aluminio, sistemas de logística, rodamientos, maquinados, moldes y dados, y herramental. Debido a que las ensambladoras son sus clientes principales, éstas han desarrollado 


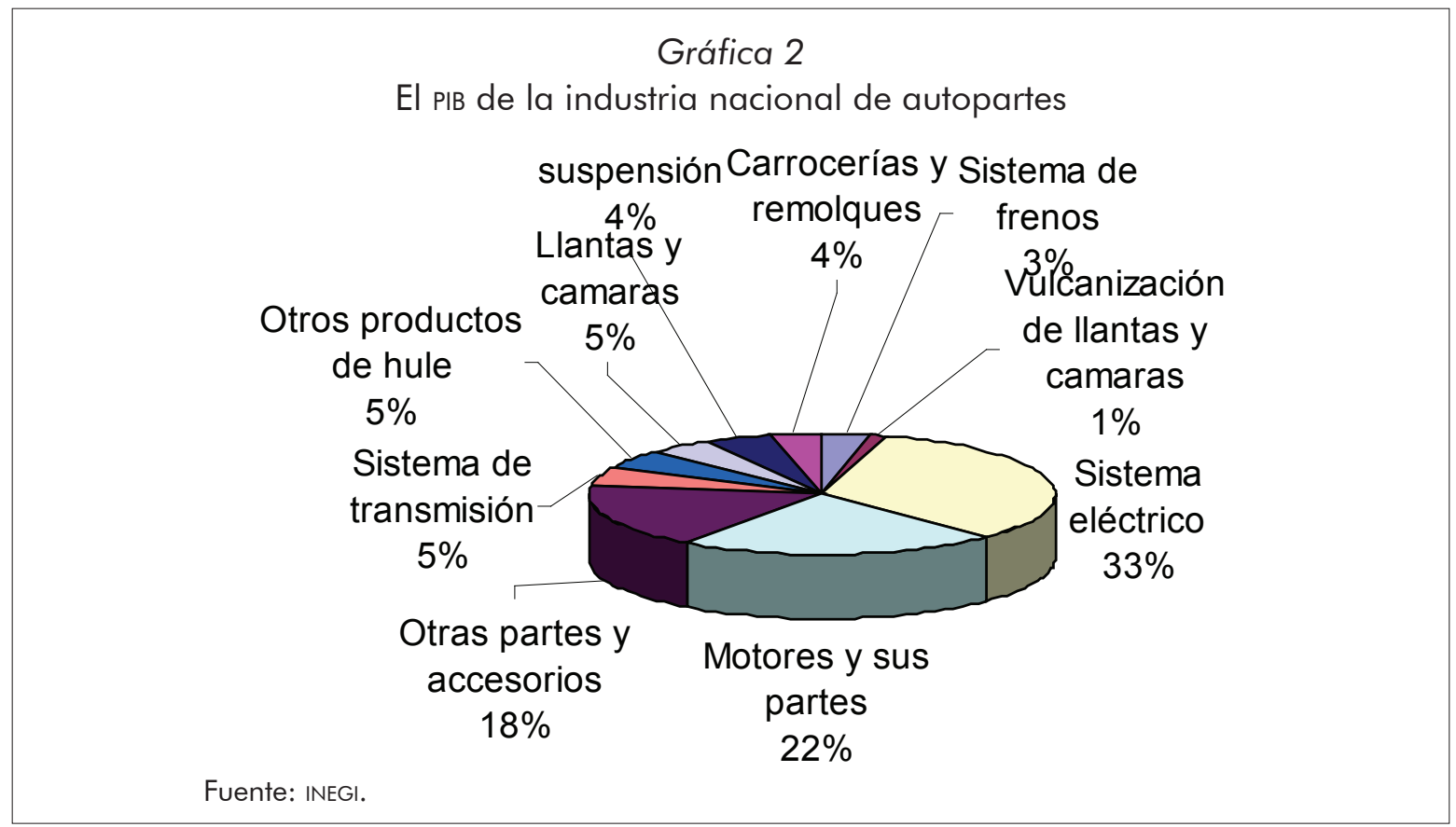

y perfeccionado diferentes sistemas para evaluar las capacidades de sus proveedores; éstos incluyen volumen de costos, tiempo de entrega, confiabilidad, calidad, desarrollo de productos, desarrollo de procesos y flexibilidad de la producción. En cuanto a la calidad, existen parámetros que se exigen a los proveedores de autopartes: certificaciones como ISO-9000, QS-9000 o VDA, ${ }^{15}$ y la disminución de índices de rechazos o retrabajos. Las normas de calidad Serie Iso-9000 fueron emitidas a finales de los años ochenta por la Organización Internacional de Normalización: ${ }^{16}$ es la norma que define los lineamientos de selección y uso de dispositivos para la administración y garantía de calidad, y asimismo permite evaluar la capacidad de los proveedores para fabricar productos o servicios con niveles de calidad estandarizados. Los patrones internacionales de calidad como las normas Iso-9000, que condicionan la entrada de productos en el mercado europeo, impulsan el esfuerzo por alcanzar el perfeccionamiento interno de la organización, lo que les permite estar dentro de esquemas comparables con los de países desarrollados (Sbragia y Cavalcanti, 2001). En 1994, bajo el apoyo de las armadoras estadounidenses establecidas en México, Chrysler, Ford y General Motors, se creó la norma de calidad QS-9000, ${ }^{17}$ considerada como una norma más acorde a las especificaciones productivas en la industria. En 1998 apareció la norma VDA 6.1 que establece nuevas tareas de la dirección de la empresa relativas a la definición de las políticas de calidad —está norma se introdujo en México en 1994.

En la industria automotriz mexicana la aparición de la norma iso tuvo efectos importantes en las relaciones comerciales y en los programas de desarrollo entre los proveedores y las empresas ensambladoras automotrices (Villavicencia y Salinas, 2002); uno de los aspectos colaterales del uso de la norma iso es la certificación, la cual tiene validez de tres años. La certificación es la evaluación de los procedimientos y modificaciones que las empresas 
realizan en busca de asegurar la calidad de sus productos y es realizada por medio de tres auditorias: una auditoria interna que se basa en normas establecidas por la propia empresa; una auditoria basada en requerimientos establecidos por el cliente; y una auditoria realizada por un auditor independiente basada en la norma reconocida internacionalmente. La industria automotriz opera en muchos casos con normas de segunda parte, es decir, establecidas por el cliente (Villavicencio y Salinas, 2002); sin embargo, los proveedores de primer nivel están obligados a contar con la norma Qs-9000, es decir, se les exige una norma internacional.

Las normas y los procedimientos de certificación en este sector han contribuido a un mayor acercamiento y cooperación en la concepción y el diseño de los productos entre proveedores y clientes. La disminución de índices de rechazos se refiere a los productos con "defectos" o que no cumplen con los estándares de calidad que se requieren, ya que existe un límite determinado en el número de partes que se pueden rechazar; la tasa de retrabajo, otro estándar de calidad, se refiere a la producción retrabajada como porcentaje de la producción total. El estándar para la producción mundial es de 200 rechazos de partes por millón (PPM) y 1.2\% de retrabajos, lo cual puede variar de acuerdo con los requerimientos de cada empresa armadora (Álvarez, 2002). Dentro de los factores que evalúan las empresas al elegir a un proveedor (Álvarez, 2002) están los siguientes: las capacidades de desarrollo de productos; el número y calificación de los trabajadores involucrados en el desarrollo de productos; el número de estaciones de diseño por computadora; ${ }^{18}$ las características de las instalaciones para realizar prototipos y pruebas; el conocimiento en métodos de diseño de herramientas; la colaboración con organizaciones que proveen tecnología; diseños y patentes registradas; gastos en investigación y desarrollo; prácticas de autogestión; información de equipos de trabajo; y uso de herramientas estadísticas y sistemas de información de la empresa. Estos requisitos no son exigidos a todos los integrantes de la cadena: normalmente se les exige a los proveedores de sistemas estandarizados que se encuentran entre los proveedores de primer nivel. En cuanto a la composición de la demanda, en 2004 las exportaciones de autopartes alcanzaron un monto de 12,805 MDD, mientras que las importaciones consistieron en 15,486 MDD. Estados Unidos es el principal destino de las exportaciones de la industria automotriz mexicana, y en menor medida Europa, Asia y América del Sur. La INA estima que en $200473 \%$ de las exportaciones de autopartes se envió a Estados Unidos, 7\% a Alemania y 4\% a Japón.

\section{Los sectores conexos y de apoyo}

El mapa 2 muestra la ubicación de los proveedores de primer nivel en la zona norte del país y el mapa 3 muestra la localización de los proveedores de primer nivel ${ }^{19}$ en el centro del país. Cifras de Bancomext afirman que existen 1,350 proveedores de la industria terminal; 281 corresponden al primer nivel y, como se observa en los mapas 2 y 3, son en su mayoría - con pocas excepciones- empresas de capital extranjero. Gran parte de estas empresas cuenta con altos niveles de tecnología y tiene importantes alianzas tecnológicas y centros para el desarrollo e innovación tecnológica, provee de componentes a las armadoras que se encuentran en el país así como las que se encuentran en el extranjero, principalmente en Estados Unidos. 
De estas empresas, 253 se encargan de la fundición, forja y estampado; 121 producen partes de plástico y hule; 30 se encargan de fabricar frenos; y 12 de la producción de vidrios; además, se estima que $236 \mathrm{de}$ estas empresas son maquiladoras, es decir, producen para otras empresas.
En el mapa 4 se encuentran los proveedores de segundo y tercer nivel, que son 1,069 empresas de tamaño mediano y pequeño. La gran mayoría está conformada por capital mexicano; como se observa, el tamaño de las empresas no ha presentado gran variación desde 2000. De estas em-

\section{Mapa 2}

La localización de proveedores de autopartes de primer nivel (zona norte)

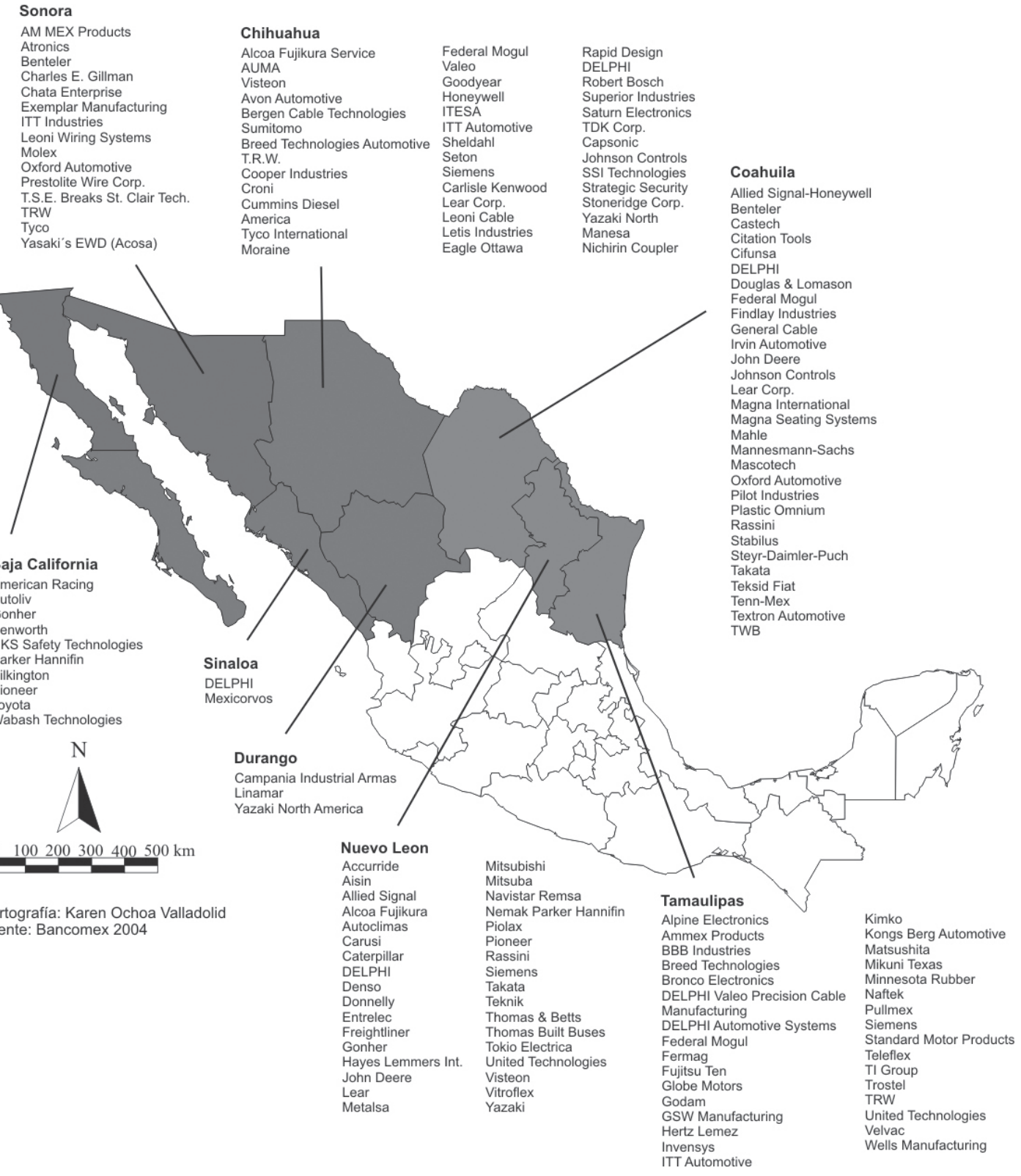




\section{Mapa 3}

La localización de proveedores de primer nivel (zona centro)

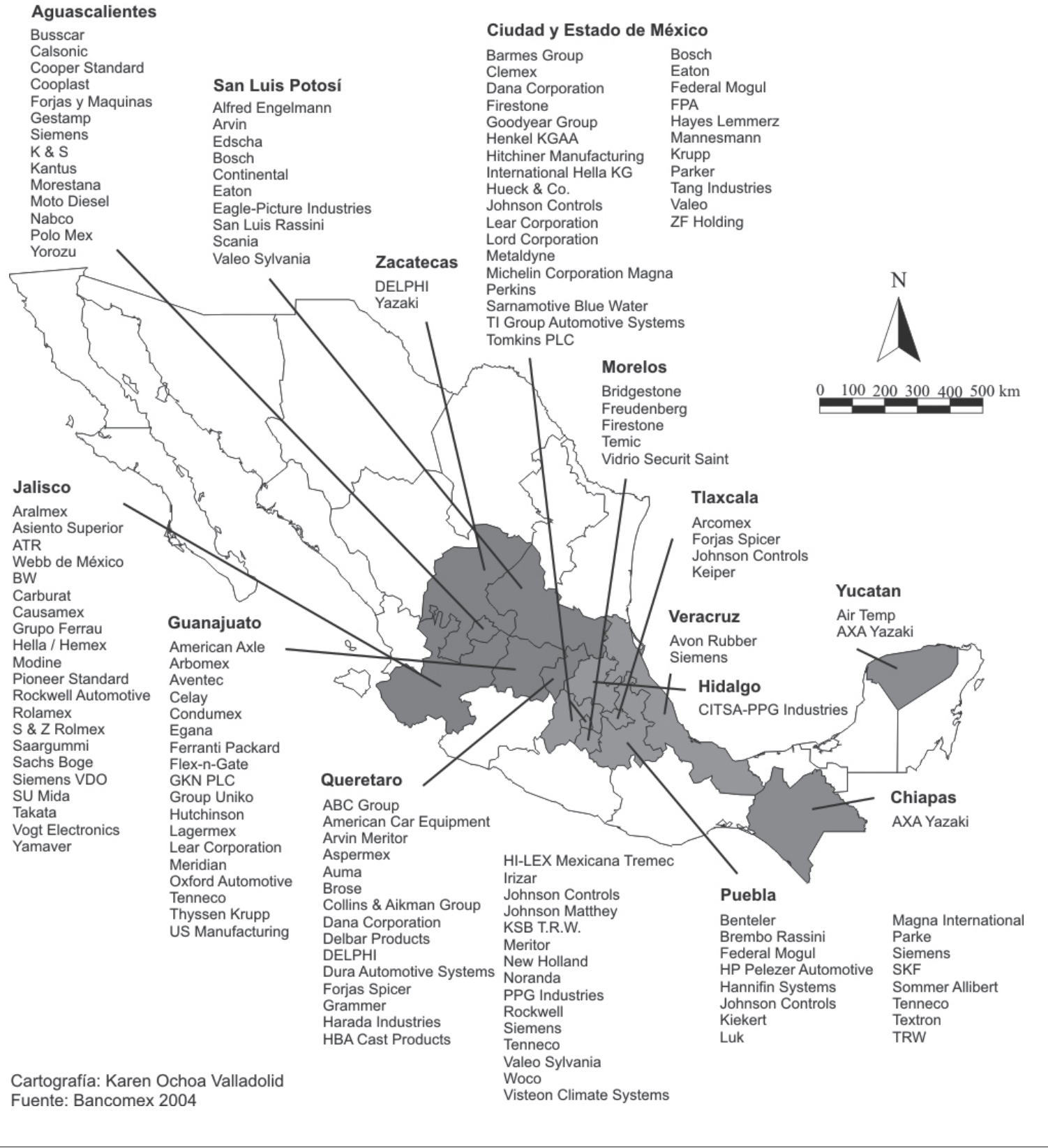

presas, 147 producen partes eléctricas, 60 se encargan de la fundición de aluminio y hierro, 25 se encargan de los maquinados y 421 producen otros componentes de vehículos. Es un reto para el país lograr complementar las tecnologías existentes con el objetivo de que estas empresas puedan ser competitivas y enfrenten los retos de la globalización. 
Mapa 4

La localización de proveedores de autopartes de segundo y tercer nivel

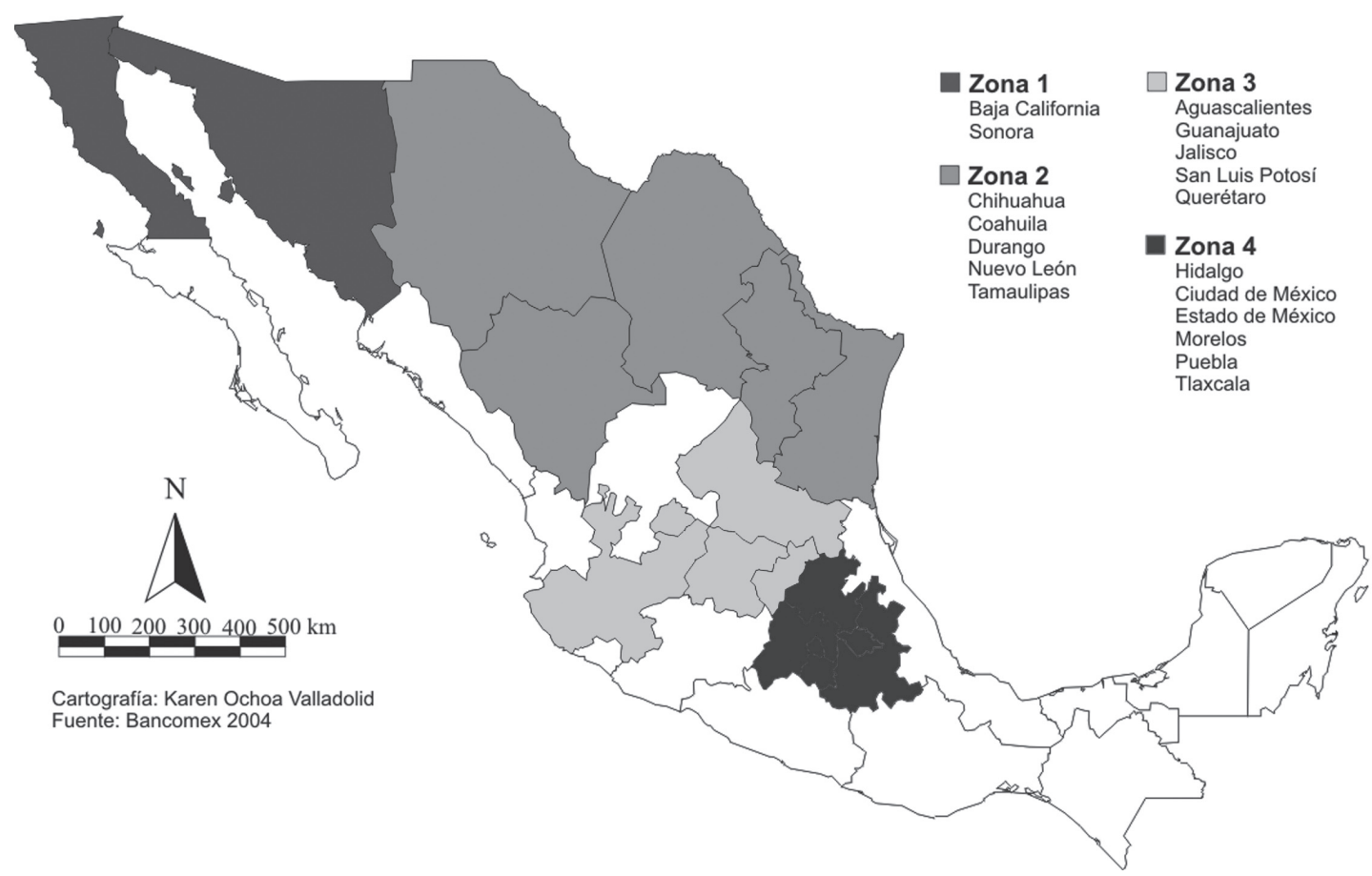

\begin{tabular}{|c|c|c|c|c|c|c|c|c|c|}
\hline & Mediana & Pequeña & Mediana & Pequeña & Mediana & Pequeña & Mediana & Pequeña & Total \\
\hline $\begin{array}{l}\text { Inyección de } \\
\text { aluminio }\end{array}$ & & & 2 & 8 & & 7 & 1 & 16 & 34 \\
\hline Frenos & & & 1 & 5 & & 8 & 1 & 15 & 30 \\
\hline Fundición & & & 1 & 6 & & 7 & & 12 & 26 \\
\hline Partes eléctricas & & 6 & 7 & 54 & 2 & 16 & & 62 & 147 \\
\hline Forjas & & & & 7 & & 12 & & 16 & 35 \\
\hline Vidrios & & & 3 & 2 & & 2 & & 5 & 12 \\
\hline Maquinados & & & & 4 & 1 & 9 & & 11 & 25 \\
\hline Hule y plásticos & & 2 & & 15 & & 18 & 1 & 85 & 121 \\
\hline Estampados & & & 2 & 43 & & 60 & 1 & 112 & 218 \\
\hline Otros & & 8 & 1 & 67 & 4 & 98 & 1 & 242 & 421 \\
\hline Total & & & & & & & & & 1069 \\
\hline
\end{tabular}

Las empresas extranjeras se encuentran en la escala más alta de la cadena productiva del sector automotriz mexicano, es decir, se encargan de fabricar y ensamblar vehículos, fabricar motores y sus partes, y la fabricación de componentes automo- trices de alto nivel tecnológico, lo que deja poco espacio para la incorporación de las empresas nacionales, o bien, reacomoda a los proveedores locales en niveles más bajos de la cadena productiva (tabla 1 ). 
Tabla 1

La distribución de la IED en la industria automotriz ${ }^{a}$

\begin{tabular}{|c|c|c|c|}
\hline $\begin{array}{l}\text { Clases de } \\
\text { actividad }\end{array}$ & De automóviles y camiones & Empresas & $\begin{array}{c}\text { Participación } \\
\text { porcentual }\end{array}$ \\
\hline Total & & 589 & 100.00 \\
\hline 384126 & Fabricación de partes y accesorios & 431 & 73.2 \\
\hline 384122 & Fabricación de motores y sus partes & 49 & 8.3 \\
\hline 384110 & Fabricación y ensamble & 46 & 7.8 \\
\hline 384125 & $\begin{array}{l}\text { Fabricación de partes accesorios para el sistema de } \\
\text { frenos }\end{array}$ & 19 & 3.2 \\
\hline 384124 & Fabricación de partes para el sistema de suspensión & 18 & 3.1 \\
\hline 384121 & Fabricación y ensamble de carrocerías y remolques & 15 & 2.5 \\
\hline 384123 & Fabricación de partes para el sistema de transmisión & 11 & 1.9 \\
\hline
\end{tabular}

a. Al mes de marzo de 2004.

Fuente: Secretaría de Economía, Dirección General de Inversión Extranjera, 2004.

Las empresas de ensamblaje han cedido más responsabilidades y riesgos a las empresas proveedoras en campos tan diversos como la calidad del producto, la investigación y desarrollo, y el mantenimiento de existencias (oIT, 2005). Es de suponer que este nuevo rol que juegan los proveedores de autopartes es muy conveniente para las ensambladoras automotrices, ya que los costos de innovación y desarrollo recaen en los proveedores, lo que explica porqué se ha incrementado la subcontratación de funciones de diseño, manufactura y ensamblado en la línea del montaje del vehículo. Como el impacto en el empleo y la sindicación es muy favorable para la ensambladora, toda la responsabilidad pasa al proveedor y libera a las ensambladoras de compromisos futuros (Álvarez, 2002). De este modo la cadena productiva de la industria automotriz se ha modificado al delegar más responsabilidades a los pro-

\section{Esquema 2}

La constelación de redes en la industria automotriz

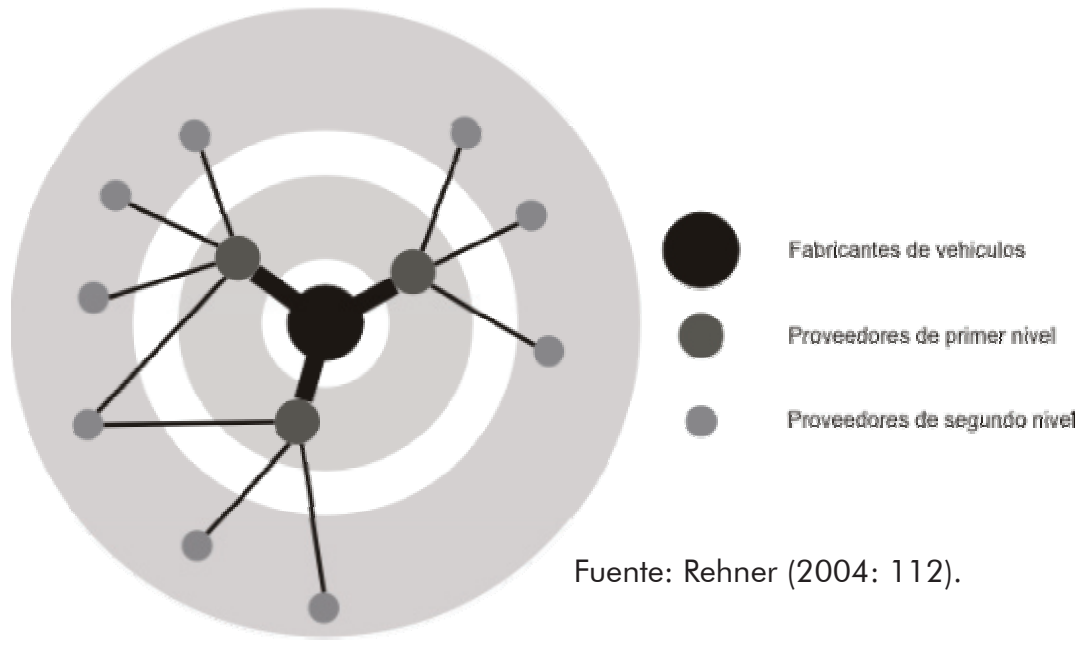


veedores de autopartes, logrando así que la cadena esté integrada por la empresa terminal y un reducido grupo de proveedores de conjuntos y subconjuntos.

En las relaciones entre los proveedores de autopartes y las empresas ensambladoras, los proveedores de primer nivel - generalmente, empresas con presencia global - son proveedores directos de las ensambladoras, mientras que éstas son abastecidas por proveedores de segundo nivel y los proveedores de tercer nivel son simples proveedores de insumos o bien desaparecen de la cadena productiva (esquema 2). Para los proveedores de autopartes la reorganización de la producción en la industria automotriz significa que las partes y componentes pueden ser armados en los diferentes modelos (Rehner, 2004). Como es importante la relación entre productor y proveedor al momento de desarrollar las partes que puedan emplearse en distintos modelos de autos, deben ser interdependientes tanto en aspectos tecnológicos como logísticos y de mercado.

Diversos estudios muestran los nuevos roles de los proveedores de la cadena productiva de la industria automotriz: el integrador de sistemas, que es capaz de diseñar componentes, subensambles y sistemas de módulos que se envían a la ensambladora y pueden colocarse o no en el vehículo; el productor global de sistemas estandarizados, que diseña sistemas estandarizados en el ámbito global que puedan ser utilizados en diferentes plataformas, además de que diseña, desarrolla y manufactura sistemas complejos y provee directa o indirectamente a la ensambladora; y el especialista en componentes y el proveedor de materias primas, que manufactura componentes para una plataforma o automóvil específico, como estampado, fundición e inyección.

\section{La estrategia, estructura y rivalidad empresariales}

Como se mencionó en el apartado anterior, las empresas fabricantes de autopartes se encuentran ubicadas cerca de las ensambladoras automotrices, es decir, en la zona norte y centro del país. La estructura del sector de autopartes se compone de la siguiente manera: los proveedores de primer nivel, que son los que proveen directamente a las empresas ensambladoras y poseen capacidades de diseño e inversión; la mayoría es de capital extranjero, empresas grandes $y$, por lo tanto, posee un alcance global que le ha permitido seguir a las ensambladoras automotrices a todos los lugares donde éstas fabriquen sus productos. Los proveedores de segundo nivel, que trabajan sobre diseños suministrados por las terminales o los proveedores de primer nivel; se les exige contar con un buen nivel de actividades técnicas así como de certificaciones ISO-9000 ó QS-9000; de acuerdo con datos de la oiT (2005), éstas presentan oportunidades de crecimiento en el comercio internacional. Y los proveedores de tercer nivel abastecen productos relativamente básicos; en la mayoría de los casos son productos con un mayor nivel de estandarización donde se requieren actividades menos sofisticadas, el nivel de inversión se considera relativamente reducido y en este tipo de proveedores las empresas compiten entre sí por medio de los precios.

Las empresas que conforman el grupo de proveedores de primer nivel proveen de partes originales a las ensambladoras automotrices; la mayoría es de capital extranjero, tiene presencia global, está a la vanguardia en tecnología, invierte importantes cantidades de dinero en investigación y desarrollo de nuevos productos, exporta directa e indirectamente la mayor parte de su producción y puede llegar a 
surtir al mercado mexicano de repuestos. Diversos estudios demuestran que estas empresas tienden a establecer alianzas estratégicas con empresas extranjeras para tener presencia en nuevos mercados, contar con tecnologías e incrementar su escala de producción.

Ciertos elementos permiten observar los cambios de mejora de procesos de producción que han llevado estas empresas (Rehner, 2004): calidad, logística, economías de escala y actividades de investigación y desarrollo. En las empresas de primer nivel se observan las siguientes características: calidad, la mayoría de estas empresas cuenta con una certificación de calidad como ISO9000 y QS-9000; sistema justo a tiempo, un factor muy importante porque las empresas proveedoras deben ajustarse a los tiempos de entrega; los incrementos en la escala de la producción que estas empresas han llevado a cabo gracias a que también abastecen en el ámbito global; la automatización de la producción e investigación y desarrollo tecnológico, aun cuando la investigación y desarrollo no es muy común en todas las empresas fabricantes de autopartes, el uso de sistemas de diseño por computadora se ha vuelto muy importante para la mejora de capacidad del diseño y muchas de las empresas lo han aplicado últimamente; la capacitación de mano de obra, elemento que juega un papel muy importante gracias al nivel de estudios de una gran proporción de los trabajadores de la industria de autopartes puede calificarse como mano de obra especializada.

Es necesario aclarar que no todas las empresas proveedoras de autopartes cumplen con los elementos señalados. Por ejemplo, una gran parte de las empresas que conforman el grupo de proveedores de segundo y tercer nivel está conformada por empresas de tamaño pequeño o mediano, realiza principalmente maquinado, fundición de hierro y aluminio, partes para el sistema eléctrico, entre otras.

Estas empresas no pertenecen a grupos multinacionales; por lo general, son empresas de capital nacional que forman parte de grupos nacionales y compiten entre ellas por precios. Respecto a sus características, se encuentran las siguientes: calidad, muchas de estas empresas no cuentan con certificaciones de calidad, sino que compiten generalmente mediante precios, es decir, el precio es un factor decisivo en la venta de sus productos; en cuanto a logística, gran parte de estas empresas ha reducido sus tiempos de entrega al abastecer pequeños lotes con mayor frecuencia y la rotación de inventarios ha disminuido notablemente; en algunos casos las empresas contratan a otras empresas especialistas en el manejo de materiales y son las encargadas de la entrega "justo a tiempo" en las plantas; generalmente, no hacen uso de economías de escala porque sólo realizan un turno en la producción; no tienen actividades de investigación y desarrollo, pero sí adquieren tecnologías ${ }^{20}$ que les permiten alcanzar los parámetros de calidad demandados por sus clientes. Una de las fortalezas de este grupo de empresas podría ser que, precisamente por su tamaño, tienen un mayor grado de flexibilidad para adoptar cambios a corto plazo en el sistema de producción.

Asimismo, estas empresas contemplan la posibilidad de éxito en la penetración de nuevos mercados como el mercado asiático, principalmente en lo que a partes de reposición se refiere. En el país se espera que puedan incursionar en nuevas líneas de productos mediante la localización de nichos de mercado, para lo que tendrían que invertir en la compra de nueva tecnología y adquisición de nuevas capacidades y competencias en las empresas. El merca- 
do de reposición es una parte importante de la cadena productiva de la industria automotriz. El diseño no es tan prescindible en este mercado, ya que las empresas que lo conforman sólo realizan copias de los diseños que fabrican otras empresas (ProArgentina, 2006). La fortaleza para las empresas de este grupo que producen para el mercado de repuestos consistirá, entonces, en la habilidad que desarrollen para adaptar y transformar determinadas piezas a las necesidades locales.

Dentro del exclusivo grupo de empresas mexicanas fabricantes de autopartes, consideradas como muy competitivas, se encuentran Nemak y Desc Automotriz, ${ }^{21}$ dos empresas proveedoras de primer nivel de la industria automotriz. Nemak es una empresa creada bajo el marco "joint venture" por Ford Motor y el Grupo Alfa. ${ }^{22}$ Esta compañía fabrica autopartes y es líder en la producción de cabezas de aluminio y monobloques, los cuales comercializa con las principales empresas armadoras de automóviles en el mundo. Para Nemak, como para el resto de las empresas de la industria de autopartes en el país, la demanda del mercado de Norteamérica es una de sus prioridades. Los ingresos de Nemak en 2000 ascendieron a 335 MDD, 26\% más que el año anterior, ${ }^{23}$ lo que impulsó a la empresa a buscar mayor presencia en el exterior y competir en nuevos mercados; prueba de ello es la inversión de 30 MDD que Nemak hizo en 2000 para construir una planta en Plzen en la República Checa. Se estima que la planta de Plzen producirá 600,000 piezas anualmente. Nemak inició sus operaciones en esta planta a partir de 2003, con lo que planea reforzar sus ventajas competitivas en cuanto al desarrollo de productos, manejo y control de costos y servicios. Nemak obtuvo seis contratos que sumaron más de 44 millones de unidades, por lo que se estima que en 2004 tuvo ventas mayores a 278 MDD.

Desc Automotriz es una subsidiaria que pertenece totalmente al Grupo Desc, ${ }^{24}$ uno de los grupos industriales más importantes de México. Desc Automotriz tiene a su cargo el desarrollo de los negocios del sector automotriz del Grupo Desc y es el principal productor de autopartes independiente, tanto por su volumen de producción como por su variedad de productos. Desc Automotriz se divide en tres grupos de negocios: transmisiones, bajo las marcas Tremec, SPT у тTC; Spicer, que integra plantas de forja y fundición con empresas como Etrac, Cardanes, Autopar, TF Victor, Enco, Forjas Spicer y Autometales; y Uniko, con las marcas Pemsa, Velcon, Comosa, Pistones Moresa, Hayes Wheels Acero y Aluminio, Morestana, Bumex, Uniko Inc. y Tecnysia. Desc Automotriz cuenta con procesos metalmecánicos de clase mundial y realiza operaciones que van desde las forjas y fundiciones, el maquinado de diversas partes de componentes y el ensamble de conjuntos mecánicos del tren motriz, hasta la comercialización de 41 líneas de productos para el mercado de equipo original y de repuesto en México y Estados Unidos.

Entre los productos que Desc Automotriz fabrica se encuentran: transmisiones manuales para vehículos ligeros y pesados (Tremec, SPT y TTC); flechas de velocidad constante (Vel-Con); estampados (Pemsa); pistones y pernos (Vehyco pistones, pistones y pernos Moresa); ejes de tracción delantera y trasera (Spicer ejes trácticos); engranes, flechas de cardán, juntas y sellos (TF Victor); punterías (Morestana); rines de acero y aluminio (sw). La marca Spicer produce: engranes córicos, forjas de precisión (forjas), flechas de tracción (cardanes), fundición hierro-nodular (autometales). Desc Automotriz Comercializadora se en- 
carga de distribuir repuestos como cajas pick up, bujías, "clutches", válvulas, anillos y partes eléctricas.

Por su dimensión y sus ventajas competitivas, Desc Automotriz ocupa una posición de liderazgo en el mercado mexicano y muchos de sus productos compiten exitosamente en Norteamérica, Sudamérica y otras regiones del mundo. En 2003, al menos 67\% de las ventas totales de la firma en autopartes correspondió a exportaciones y atiende al mercado de equipo original con $81 \%$ de sus ventas. Mantiene alianzas estratégicas y contratos de asistencia técnica con firmas como: Dana Corporation, GKN Industries, Delphi y Hayes Lemmerz International. Sus productos se sustentan en desarrollos tecnológicos propios y de sus socios. El volumen de las ventas anuales de Desc Automotriz asciende a 390 MDD y emplea a 8,794 personas. En 2003 la empresa tenía un valor de 1,080 MDD. Entre sus clientes más importantes destacan Daimler-Chrysler, Ford, General Motors, Kenworth, John Deer, Navistar, Renault-Nissan, Sangyong, Volkswagen y ZF-Meritor. Desc Automotriz planeaba destinar entre 150 y 200 MDD para inversión en 2005.

Debido a lo anterior y la importancia que tienen las empresas de autopartes en la cadena productiva de la industria automotriz mexicana, se enfatiza la necesidad que tienen las empresas de lograr una mayor capacidad de manufactura, de tecnologías, centros de desarrollo e innovación, alianzas estratégicas, en fin, alcanzar una serie de factores que las vuelvan competitivas. Para contribuir así al desarrollo de los fabricantes de componentes automotrices, el gobierno mexicano brinda apoyo por medio de Bancomext con créditos a empresas exportadoras, apoyo a proveedores locales y estímulos a la inversión extranjera y alianzas en este sector.

\section{El papel del gobierno}

Diversos estudios han presentado un debate sobre la intervención del gobierno, respecto a si deben ser neutrales al tipo de sectores en los que se especialice el país o si deben promoverlos. El proteccionismo sectorial — no es nada nuevo, pues las naciones protegen a sus sectores desde hace mucho tiempo- afirma que el nuevo elemento del proteccionismo es negociar la participación del mercado sector por sector (Gilpin, 1990).

Una adecuada política industrial dirigida a asociar la incorporación de tecnologías con el incremento y los procesos de producción, así como la penetración en nuevos mercados, puede contribuir a que los incrementos de competitividad ayuden efectivamente a resolver los problemas de los costos relativos (Beckerman y Sirlin, 1998). Por esto se entiende que la política industrial puede utilizarse para modificar los precios relativos y mejorar la competitividad de la economía mediante incrementos generalizados de la productividad. Desde el establecimiento de las primeras plantas automotrices en México, el gobierno ha tratado de impulsar el desarrollo de la industria a través de la adopción de medidas de fomento y ha logrado que el sector automotriz pase de ser un simple armador e importador a un productor de sus principales insumos y genere un alto valor agregado. Sin embargo, desde su inicio se observa cómo, debido a los requerimientos de la industria automotriz, se produjo un déficit muy grande en la balanza comercial; como resultado, el gobierno mexicano emitió una serie de decretos para fomentar la producción interna de los insumos y de esta manera se sustituyeron las importaciones para fortalecer la industria.

Antes del primer decreto de 1962, el 
gobierno impulsaba el asentamiento y desarrollo de las plantas ensambladoras mediante de la reducción de tarifas de importación para autopartes en $50 \%$, así como mediante exenciones fiscales a la inversión. En 1940 se importaba cerca de 95\% de los componentes automotrices para el ensamble, pero veinte años después se redujo a $80 \%$.

Para reducir este déficit de la balanza comercial en la industria automotriz el gobierno mexicano publicó un decreto en 1962 el cual estaba encaminado a fomentar la industria de autopartes. Este decreto establecía un porcentaje mínimo de contenido de componentes locales equivalente a $60 \%$ en los vehículos armados en México - a este instrumento se le conoce también como grado de integración o $\mathrm{GIN}^{25}$ - Para cumplir con el decreto de 1962 las empresas automotrices realizaron importantes inversiones en activos fijos y, en consecuencia, la industria presentó un importante crecimiento. $\mathrm{Su}$ participación en el PIB manufacturero se elevó considerablemente, pero se presentó un aumento en el déficit comercial del sector; lo anterior puede atribuirse al crecimiento de la demanda interna y externa.

Los decretos subsecuentes trataron de equilibrar la balanza comercial. El decreto de 1972 mantuvo el requisito de contenido local de $60 \%$ para el mercado nacional, para incentivar las exportaciones se redujo a $40 \%$ el requisito de contenido local y se otorgó un subsidio a las exportaciones de $30 \%$ sobre el precio de lista. Sin embargo, las exportaciones de autopartes siguieron creciendo, lo que agravó aún más el déficit comercial. La crisis financiera de 1982 - aunada al desarrollo de la industria de autopartes - tuvo como resultado un incremento en las exportaciones del sector.

Dentro de un marco de apertura comercial se emitió el decreto de 1989 el cual giró en torno a un mayor nivel de competitividad internacional. En este decreto se permitió la importación de modelos equivalentes cuando había un diferencial de precios netos; la importación de vehículos extranjeros se volvió exclusiva de los productores de la industria terminal, medida que deja en sus manos el control de la oferta. Debido a lo anterior, las empresas automotrices estaban obligadas a tener saldos positivos en la balanza comercial y se sustituyó la regla de contenido nacional para incorporar el requisito de mantener $36 \%$ del valor agregado nacional (vAN) en sus productos. La ventaja de esta nueva regla es que le otorga mayor flexibilidad a los productores de la industria terminal permitiéndoles escoger los productos que pueden ser adquiridos en el mercado doméstico. Esto provoca una mayor competencia en el mercado de autopartes y obliga a estos fabricantes a aumentar su competitividad internacional.

Los datos anteriores muestran que la industria automotriz creció bajo un esquema de proteccionismo a través de barreras al comercio de los productos finales y bajos niveles de aranceles para los insumos. La protección y las exenciones fiscales a la inversión, combinadas con las expectativas de crecimiento del mercado interno, incentivaron la localización en México de empresas con capital extranjero para producir bienes finales, aunque los niveles de competitividad internacional de la industria se mantuvieron bajos durante ese periodo. Estas medidas obligaron a las empresas multinacionales que permanecieron en el país a incrementar su inversión para el desarrollo de la industria de autopartes, aunque los niveles de competitividad no mejoraran sustancialmente. Las medidas adoptadas en 1989 permitieron que el sector automotriz se volviera más competitivo, ya 
que la industria de autopartes enfrenta ahora una mayor competencia en el mercado interno. El incremento de competitividad, aunado a la restricción del capital extranjero, permitió la adquisición y asimilación de tecnología, y una liberalización adicional del sector permitiría incrementar aún más su eficiencia (Kim y Kessel, 1995).

En cuanto a la participación del gobierno mexicano en la formación del capital humano, la promoción del esfuerzo científico y tecnológico en los años veinte tuvo logros moderados (Unger, 1995). Las iniciativas principales consistieron de dos etapas: la creación de instituciones como universidades en Michoacán, Yucatán, San Luis Potosí y Guadalajara; en esta etapa destacó la creación en 1929 de la Universidad Autónoma de México (UAM) así como el desarrollo de sus facultades e institutos. No obstante la larga lista de instituciones creadas para el fomento de la ciencia, tecnología e investigación, aún era visible el subdesarrollo científico y tecnológico, así como la dependencia del exterior que existía en el país.

Uno de los logros principales de la política para el desarrollo tecnológico e industrial mexicano fue la creación del Conacyt en diciembre de 1970, y durante 1972 y 1973 la promulgación de leyes para el control de transferencia tecnológica y de la inversión extranjera. La política nacional de ciencia y tecnología buscaba principalmente el paso de una etapa de imitación y retraso a una de creatividad científica y tecnológica (Unger, 1995). Las leyes promulgadas buscaban, por su parte, reducir los costos de transferencia de tecnología del exterior, y permitir que se generen capacidades competitivas de la industria local. Desafortunadamente, los esfuerzos logrados superaban las capacidades de las leyes creadas y del Conacyt, lo que hizo que no se cumplieran los objetivos deseados al aplicar estos elementos. El análisis de algunos indicadores y elementos de la política oficial de ciencia y tecnología (CyT) y de investigación y desarrollo (I\&D) en México, indica el insuficiente e inadecuado papel que el gobierno mexicano le ha otorgado a la política de ciencia y tecnología en su vinculación con el sistema productivo nacional (Olmedo, 2001).

Dentro de los programas de apoyo que diseña el gobierno mexicano para fomentar el desarrollo y la competitividad de las empresas del sector de autopartes, destacaban los créditos financieros y los programas orientados a las exportaciones. En los años ochenta, durante el periodo de crisis económica y de políticas de ajuste y liberalización comercial, el gobierno mexicano decidió desarrollar programas que fomentaran las exportaciones de las empresas establecidas en el país. Los programas para el fomento de exportaciones que se aplicaron -y que incluían a la industria automotriz - son: el programa para la maquila, el cual consistía en una serie de deducciones de aranceles y permisos, así como de simplificación de trámites para las operaciones de la industria maquiladora en el país; Pitex, un programa de importación temporal para la producción de artículos de exportación bajo el cual se deducían los pagos de aranceles sobre la importación de insumos que eran incorporados a productos exportables. También se exceptuaban los bienes de capital que se requerían para tal propósito; DrawBack, programa que consistía en devolver a los exportadores el valor del impuesto general de importación pagado por bienes o insumos importados que se incorporaban a mercancías de exportación; Altex, programa que intenta simplificar los trámites y permite a las empresas altamente exportadoras prescindir de los trámites mediante agentes 
aduanales registrados; y Ecex -empresas de comercio exterior - que impulsa la comercialización de mercancías mexicanas en los mercados internacionales.

El sector de autopartes se ha desarrollado porque el gobierno de México reconoce su importancia para la economía mexicana. Sumado a los programas anteriores, forma parte de una estrategia que permite fomentar la competitividad de la industria de autopartes por medio de: desarrollo y diversificación de las exportaciones; integración de la cadena automotriz a través del desarrollo de proveedores del segundo y tercer nivel; y promoción para la atracción de inversión extranjera al sector con énfasis en las alianzas estratégicas de pequeñas y medianas empresas del exterior con las contrapartes mexicanas a fin de fortalecer e incrementar el valor agregado de la cadena productiva.

De acuerdo con Bancomext, la unidad sectorial contempla un programa de apoyo a las exportaciones indirectas de equipo original del sector, el cual ha identificado 14 grupos de productos - que agrupan a 86 proyectos de exportación - en los cuales se trabajará a fin de incrementar su valor agregado a través de un programa de desarrollo de proveedores e inversión extranjera. También, se desarrollarán acciones para que las empresas mexicanas diversifiquen sus clientes y mercados con productos de repuestos, accesorios y partes de colisión. Los mercados objetivo a atender serán: Latinoamérica, Europa y Asía. Los resultados que se pretenden alcanzar son: 105.5 MDD de ventas de exportación con apoyo a 130 empresas. Los proyectos serán desarrollados en conjunto con 16 Centros Bancomext y 27 consejerías, así como organismos de la industria como: la Asociación Nacional de Productores de Autobuses, Camiones y Tractocamiones (ANPACT), la Industria Na- cional de Autopartes (INA), las Secretarías de Desarrollo Económico de nueve estados (Sedeco), la Secretaría de Economía, así como con los organizadores de los eventos Automecánika y Expo Rujac. Los estados que participarán con el mayor número de empresas son México y Baja California con 18 exportadoras cada uno, luego el Distrito Federal y Querétaro con 14 compañías.

Estos son a grandes rasgos los esfuerzos del gobierno mexicano para fomentar la competitividad y el desarrollo del sector de autopartes. Como se mencionó, la estrategia desarrollada para el sector de autopartes incluye sólo empresas del grupo de segundo y tercer nivel, que son los espacios en la cadena de producción que dejaron libres las ensambladoras automotrices y las empresas multinacionales proveedoras de autopartes, ubicadas en el primer nivel de la cadena productiva.

\section{El papel de la causalidad}

De acuerdo con Porter, el papel de la casualidad o azar puede afectar el nivel de competitividad de un sector o país. La reacción de las empresas de un sector o país ante situaciones como devaluaciones, crisis económicas o incrementos en el precio del petróleo puede afectar seriamente a los otros factores que determinan la competitividad de un sector, en tanto que la situación del resto de los factores puede contribuir también a la fortaleza del sector de manera tal que responda de forma positiva o negativa ante un hecho difícil de controlar como los hechos casuales.

Como se dijo en apartados anteriores, México ha sufrido diversas crisis económicas que han repercutido considerablemente en la formulación y aplicación de distintas políticas económicas. En cuanto al sector de autopartes, por lo general, los 
efectos han sido relativamente positivos; un ejemplo de ello es la crisis de los setenta, de la que resultó una serie de decretos que culminó con el de 1977, el cual modificó el grado de contenido local de las exportaciones de la industria automotriz y eliminó los controles a los precios y las cuotas de producción. Todas estas medidas tuvieron el propósito de apoyar a las empresas con capital nacional.

Las devaluaciones causadas por la crisis de 1982 mejoraron la situación de la industria automotriz $-\mathrm{y}$ directamente el sector de autopartes - porque los precios se redujeron y su competitividad aumentó. Asimismo, el decreto de 1989 pretendía fomentar el desarrollo de la industria automotriz mexicana e incentivar una mayor participación de las autopartes mexicanas en la cadena productiva automotriz. La crisis de 1994 y la entrada en vigor del TLCAN tuvieron efectos importantes en el sector de autopartes. Se establecieron nuevas plantas automotrices y se reestructuraron las plantas existentes. La posición geográfica de México así como la firma del TLCAN volvieron aún más atractiva la inversión y la entrada de nuevas empresas al país. Con la entrada en vigor del TLCuem el 1 de enero de 2000, México se vuelve la plataforma de exportación para el mercado más grande del mundo -Estados Unidos-, lo que beneficia a las empresas fabricantes de autopartes establecidas en el país.

\section{Conclusión}

La industria automotriz en México debe su desarrollo básicamente al impulso de las empresas automotrices de Estados Unidos, Japón, Francia y Alemania, ya que la estrategia de internacionalización de las firmas automotrices líderes en el mundo las llevó a desconcentrar su proceso productivo hacia países con menores costos de producción. Las plantas de montaje así como las empresas proveedoras de los componentes básicos se ubicaron en países en desarrollo como el nuestro.

Posteriormente, con el auge exportador los gobiernos trataron de incentivar e incluso presionar a las firmas para que contribuyeran a mejorar la balanza comercial del país. Actualmente, gobiernos como el mexicano ofrecen mayores facilidades a las empresas extranjeras para captar inversión extranjera directa, después de que países como China se abrieran al comercio y algunos países de Europa del Este se integraran a la Unión Europea, y se volvieran fuertes competidores en la búsqueda de inversión extranjera directa.

El estudio de la evolución de la industria automotriz mexicana indica que el capital nacional no se ha integrado al capital extranjero, porque todas las armadoras son de otros países. Sin embargo, gracias a estas firmas el país se industrializa y recibe inversión extranjera directa e inversión en capital humano, como en el caso de vw México. El capital del sector de autopartes mexicano tampoco se ha integrado al foráneo porque la gran mayoría de las empresas proveedoras de primer nivel de la industrial terminal es de origen extranjero. Con excepción de algunas empresas pertenecientes a "holdings" mexicanos, como el caso de Nemak, o bien de la unión de empresas extranjeras y nacionales, como el caso de Desc Automotriz, las empresas mexicanas no tienen presencia en el ámbito mundial. Las empresas proveedoras de autopartes de segundo y tercer nivel son de tamaño mediano y pequeño, y proveen tanto a la industria terminal como a las proveedoras de primer nivel; la mayoría de las empresas pequeñas se caracteriza por proveer al 
mercado nacional de repuestos. Se observa que no existe un desarrollo significativo en el sector de autopartes mexicano, ya que la mayoría de las PYME que integra al sector se caracteriza por producir componentes de bajo nivel tecnológico y está ubicada en los niveles más bajos de la cadena productiva de la industria automotriz.

La estructura del sector de autopartes mexicano muestra que las empresas proveedoras de primer nivel -multinacionales extranjeras-pueden aprovechar las ventajas que ofrecen los tratados de libre comercio que ha suscrito México para colocar sus productos en mercados externos, tanto en el de equipo original como en el de repuestos, porque los fabricantes de autopartes de primer nivel operan con tecnología traída de su lugar de origen y generalmente los componentes que fabrican son muy competitivos.

Debido a que los proveedores de autopartes mexicanos se encuentran en los niveles bajos de la cadena productiva de la industria automotriz, por lo que se asume que sus productos tengan un bajo contenido tecnológico y que la mayoría de estas empresas sea PYME, será muy difícil que comercialicen sus productos exitosamente en los mercados externos. Aun con los proyectos de financiamiento y las estrategias de apoyo que el gobierno mexicano ofrece a las PYME fabricantes de autopartes, éstas no cuentan con los factores que contribuyan a otorgar competitividad sus productos. A pesar de que el gobierno mexicano conoce la situación de los proveedores de autopartes, así como los problemas a que se enfrentan, no se han diseñado estrategias que brinden financiamiento, difusión y estímulos financieros para fomentar las exportaciones de autopartes mexicanas.

Asimismo, el gobierno mexicano reconoce en el Plan Nacional para el Desarrollo 2001-2006 la importancia de las PYME de autopartes para la economía mexicana y la necesidad de una mayor integración de estas empresas a la cadena productiva de la industria automotriz. Sin embargo, no se ha diseñado un plan maestro o un proyecto futuro donde se presente una estrategia de largo plazo que, en conjunto con las empresas proveedoras de autopartes, permita el desarrollo de las mismas y las integre más a la cadena productiva de la industria automotriz. No hay que olvidar que si estas empresas no cuentan con la tecnología necesaria para el desarrollo de sus productos, capacidad de innovación, mejoras en los sistemas de logística, así como otros factores que les brinden competitividad, no podrán aprovechar las oportunidades que los acuerdos internacionales que México firma - como el TLCUEM ${ }^{26}$ - para que compitan con éxito tanto en el mercado interno como en el exterior.

Las transformaciones de la industria automotriz han logrado tocar todos los niveles de la cadena productiva y la evidencia empírica demuestra que sólo las empresas que se han adaptado en el menor tiempo posible y han sido capaces de responder a 
las demandas de la industria automotriz, han sobrevivido a los cambios del modelo productivo, la internacionalización y la especialización de esta industria. my

\section{Notas}

1 Según cifras de Bancomext, en 2003 el sector automotriz tuvo un superávit de 8.54 MMDD.

2 Algunos autores difieren sobre el número de etapas de desarrollo de la industria automotriz. Este trabajo toma las tres etapas de Juan Carlos Moreno Brid porque son más apropiadas para el análisis del tema de estudio.

3 En ellas se iniciaron las manufacturas de fundición y maquinado de las partes para motor, como cigüeñales, monobloques, árbol de levas y otros.

4 En los años setenta el agotamiento del modelo de sustitución de importaciones también vino acompañado de un descenso en el crecimiento de la industria de autopartes, muy por debajo del de la industria automotriz.

5 En 1992 México firmó un TLC con Chile y la liberación del sector automotriz se llevaría a cabo en 2004.

6 De acuerdo con Bancomext, en 2003 la balanza comercial de la industria automotriz tuvo un saldo positivo de 8.5 millones de dólares.

$7 \quad$ No es así en todo el país, es decir, la infraestructura en México aún está muy localizada, ya que existen zonas que no tienen servicios de agua potable y luz o calles pavimentadas.

8 De acuerdo con el censo más reciente del INEGI.

9 De acuerdo con la información de los Censos Económicos 2004 de INEGI.

10 Según los resultados educativos de las Estadísticas Sociodemográficas de INEGI.

11 De acuerdo con la Secretaría de Educación Pública, gracias al Programa Nacional de Educación 2001-2006 se han obtenido logros importantes en cuestiones de equidad, calidad y gestión educativa.

12 Afortunadamente, aunque pocos, existen casos de cooperación para la investigación entre empresas y universidades en el país.

13 Nos referimos a las soluciones rápidas a pequeños problemas en el proceso productivo y problemas a corto plazo que no pueden ser resueltos de inmediato.
14 Este término se refiere a Aires Acondicionados y Combustibles.

15 La norma alemana vDA 6.1 (emitida por la Verband der Automobilindustrier er, V.) apareció en 1998 y es conocida como el Sistema de Gestión de la Calidad para la industria automotriz alemana. Es considerada como la más exigente para las empresas de autopartes; está dividida en dos partes, la primera sobre la gestión y la segunda sobre los productos y procesos (VDA, 2006).

16 La Iso (Internacional Organization for Standarization) es la organización más grande en el mundo y se encarga del desarrollo de altos estándares de calidad (Iso, 2006).

17 De acuerdo con Villavicencio y Salinas (2002), esta norma de Quality Systems Standards se basa en los manuales de estándares de calidad de las impulsoras de esta norma: Chrysler, Ford y General Motors.

18 También conocido como CADCAM, que significa sistemas de diseño por computadora.

19 También conocidos con el término "Tier One suppliers".

20 Estas compras van dirigidas a los sistemas de información que ayudan a la administración de las actividades de la empresa como manufacturas, ventas y abastecimiento, o invierten en sistemas de cómputo para control de procesos.

21 Anteriormente, Unik.

22 Holding mexicano cuya matriz se encuentra en Monterrey.

23 Morales (2003: 199) afirma que esto se dio aun cuando la empresa enfrentó ciertos factores negativos como la posición del peso mexicano frente al dólar estadounidense y el incremento en los costos indirectos de producción como el gasto en energéticos.

24 Grupo Desc es un holding que se fundó en 1973 con el nombre de Desc, Sociedad de Fomento Industrial, SA de cV y que actualmente organiza sus empresas en tres divisiones: la química-petroquímica, la metalmecánica y la de alimentos. Para conocer la historia de este grupo industrial, véase su sitio en el Internet: http://www.desc.com.mx.

25 Este desaparece con el Decreto de 1989 donde se utiliza como medida el valor agregado nacional (vAN).

26 Tratado de Libre Comercio Unión EuropeaMéxico, que entró en vigor el 1 de enero de 2000 .
MÉXICO YLACUENCADEL PACÍFICO vol. 8, núm. 26 / septiembre-diciembre de 2005 


\section{Referencias bibliográficas}

Álvarez, M. (2004), "Cambios de la industria automotriz frente a la globalización: el sector de autopartes en México", en Contaduría y Administración (UNAM), núm. 206, pp. 29-49.

Arteaga, A. y C. Gutiérrez (1996), "La reestructuración de la industria automotriz en México y algunas repercusiones laborales", en G. Bensusán y $\mathrm{A}$. Arteaga (coord.), Integración regional y relaciones industriales en América del Norte, UAM-I/FLACSO, México, DF, pp. 229-302.

Arteaga, A. y J. Micheli (1993), "Desarrollo de la manufactura: estrategia y ventajas competitivas", en A. Covarrubia y B. Lara (coord.), Relaciones industriales y productividad en el Norte de México: tendencias y problemas, El Colegio de Sonora y Fundación Friedrich Ebert, México, 13-28.

Beckerman, M. y P. Sirlin (1998), "Política industrial y estabilización, apertura e integración económicas", en Comercio Exterior (México), vol. 48, núm. 7, pp. 517-527.

Campos, E. (2003), “Unik: invertir desinvirtiendo", en Mundo Ejecutivo (México), pp. 278-279.

Carrillo, J. y M. Ramírez (1997), "Reestructuración, eslabonamientos productivos y competencias laborales en la industria automotriz de México", en M. Novick y M. Gallart (coord.), Competitividad, redes productivas y competencias laborales, OITCinterfor/CIID-CENEP, Montevideo, pp. 351-391.

Charles River Associates (2003), "Competitiveness Factors for Attracting and Maintaining Automotive Investment: Comparison between Canada and México", disponible en http://strategis.ic.gc. ca/epic/internet/inauto-auto.nsf/en/am01399e. html, consultado el 10 de noviembre de 2003.

Correa, C. (2001), "Contribución de la universidad a la innovación de la empresa en América Latina", en B. Olmedo y J. Solleiro (coord.), Políticas industriales y tecnológicas para las pequeñas y medianas empresas: experiencias internacionales, Ed. Porrúa, México, DF, pp. 35-55.

Eggers, L. y M. Arellano (2000), "Las 100 mejores plantas manufactureras de México. El nuevo México industrial", en Mundo Ejecutivo (México), vol. 26, núm. 258, pp. 20-38.

Gilpin, R. (1990), La economía política de las relaciones internacionales, Grupo Editorial Latinoamericano, Buenos Aires, 449 pp.

Hernández, A. (2003), "Mercado automotriz: competitivo", en Revista Negocios Internacionales Bancomext, pp. 6-9.

Kim, C. y G. Kessel (1995), "Características del desarrollo tecnológico y su contribución al crecimiento de la producción industrial y al comercio exterior: el caso de México", en P. Mulás (coord.), Aspectos tecnológicos de la modernización industrial de México, FCE, México, DF, pp. 113-135.
Micheli, J. (1994), Nueva manufactura, globalización y producción de automóviles en México, UNAM-FE, México, DF, pp. 73-237.

Morales, J. (2000), "La industria de autopartes", en Mundo Ejecutivo (México), vol. 26, núm. 258, pp. 165-180.

Moreno, J. (1995), "Cambios estructurales en la industria automotriz de México (1977-1989)", en G. Van Liemt (coord.), La reubicación internacional de la industria: causas y consecuencias, OIT, Ginebra, pp. 291-312.

OCDE (2006), "Panorama de la educación 2004", disponible en http://www.ocde.org/dataoecd/32/47/33732172.pdf, consultado el 5 de febrero de 2006.

OIT (2005), "Tendencias de la industria automotriz que afectan a los proveedores de componentes", Programa de actividades sectoriales, Ginebra, pp. 1-170, disponible en http://www.ilo.org/public/ spanish/dialogue/sector/techmeet/tmtem05/tmtemr.pdf, consultado el 24 de noviembre de 2005.

Olmedo, B. (2001), "Reflexiones en torno a algunos aspectos de la investigación y el desarrollo en México", en B. Olmedo y J. Solleiro (coord.), Políticas industriales y tecnológicas para las pequeñas y medianas empresas: experiencias internacionales, Ed. Porrúa, México, DF, pp. 223-235.

Porter, M. (1991), La ventaja competitiva de las naciones, Javier Vergara, Buenos Aires, 1025 pp.

ProArgentina (2006), "Autopartes", en Serie de Estudios Sectoriales, Subsecretaría de la Pequeña y Mediana Empresa y Desarrollo Regional, Ministerio de Economía y Producción, Buenos Aires, disponible en http://www. proargentina.gov.at, consultado el 3 de enero de 2006.

Rehner, J. (2004), "Netzwerken und Kultur: Unternehmerisches Handeln deutscher Manager in Mexiko", Wirtschaft und Raum, München, VVF, 248 pp.

Rodríguez, J. y M. Cota (1999), "Proceso de localización de la industria automotriz en México", en Carta Económica Regional (UdG), vol. 12, núm. 67, pp. 34-38.

Sbragia, R. y M. Cavalcanti (2001), "El comportamiento innovador de las pequeñas, medianas y grandes empresas latinoamericanas", en B. Olmedo y J. Solleiro (coord.), Políticas industriales y tecnológicas para las pequeñas y medianas empresas: experiencias internacionales, Ed. Porrúa, México, DF.

Tamariz, A. (1999), "Nichos de mercado en Alemania", en Revista Negocios Internacionales Bancomext, pp. 9-11.

Unger, K. (1995), “El desarrollo industrial y tecnológico mexicano: estado actual de la integración industrial y tecnológica", en P. Mulás (coord.), Aspectos tecnológicos de la modernización industrial de México, FCE, México, DF, pp. 44-80.

Villavicencio, D. y M. Salinas (2002), "La gestión del conocimiento productivo: las normas ISO y los sistemas de aseguramiento de calidad", en Comercio Exterior (México), vol. 52, núm. 6, pp. 508-520. 